Messenger RNA expression prof ile of sl eep-rel at ed genes in peri pheral bl ood cel Is in pati ent s with chroni c ki dney di sease

\begin{tabular}{|c|c|}
\hline 著者 & 北島 信治 \\
\hline 著者別表示 & Ki t aj i ma Shi nj i \\
\hline $\begin{array}{l}\text { jour nal or } \\
\text { publ i cat i on titl e }\end{array}$ & 博士論文本文Ful I \\
\hline 学位授与番号 & 13301乙第2071号 \\
\hline 学位名 & 博士 (医学) \\
\hline 学位授与年月日 & $2015-12-31$ \\
\hline URL & ht t p: //hdl . handl e. net /2297/45553 \\
\hline
\end{tabular}




\title{
Messenger RNA expression profile of sleep-related genes in peripheral blood cells in patients with chronic kidney disease
}

\author{
Shinji Kitajima ${ }^{1}$ Yasunori Iwata ${ }^{1,2,3,4} \cdot$ Kengo Furuichi $^{1,2,3,4} \cdot$ Akihiro Sagara $^{1,2,3,4}$. \\ Yasuyuki Shinozaki ${ }^{1,2,3,4} \cdot$ Tadashi Toyama ${ }^{1,2,3,4} \cdot$ Norihiko Sakai $^{1,2,3,4}$. \\ Miho Shimizu ${ }^{1,2,3,4} \cdot$ Takeshi Sakurai ${ }^{1,2,3,4} \cdot$ Shuichi Kaneko ${ }^{1,2,3,4} \cdot$ Takashi Wada $^{1,2,3,4}$
}

Received: 12 February 2015 / Accepted: 23 July 2015/Published online: 20 September 2015

(C) Japanese Society of Nephrology 2015

\begin{abstract}
Background Various sleep abnormalities, such as delayed sleep onset, frequent awakening and daytime sleepiness, deteriorate the quality of life in patients with chronic kidney disease (CKD), including those on haemodialysis (HD). Although there are some candidate causative molecules in the central nervous system, the contribution of peripheral blood cells (PBCs) remains unclear. In this study, we performed polysomnographic analysis in CKD patients and used PBCs to examine the expression of genes related to sleep and wakefulness states.

Methods Polysomnographic analysis was performed in 9 CKD patients and 6 controls. Genes related to sleep and wakefulness were evaluated by RNA microarray in 19 subjects, including CKD patients and control subjects.

Results Polysomnographic analysis revealed that the duration of the rapid eye movement (REM)/non-REM phases during total sleep time was different between CKD patients and healthy controls. In mRNA microarray evaluation, hierarchical clustering analysis showed different
\end{abstract}

Shinji Kitajima

kitajimajima@ybb.ne.jp

Takashi Wada

twada@m-kanazawa.jp

1 Division of Nephrology, Kanazawa University Hospital, 13-1 Takara-machi, Kanazawa 920-8641, Japan

2 Department of Molecular Neuroscience and Integrative Physiology, Faculty of Medicine, Kanazawa University, Kanazawa, Japan

3 Department of Disease Control and Homeostasis, Kanazawa University Hospital, Kanazawa, Japan

4 Department of Laboratory Sciences, School of Health Sciences, Kanazawa University, Kanazawa, Japan patterns of sleep-related gene expression in HD patients. mRNA expression levels of GABA receptor (GABBR2), noradrenaline receptor (ADRA1A), dopamine receptor (DRD1) and histamine receptor (HRH1) showed an inverse correlation with renal function. Moreover, the mRNA expression of orexin and its receptor (HCRTR1 and HCRTR2) was also inversely correlated with renal function.

Conclusion These data indicate that the expression of sleep-related genes in PBCs of CKD patients may be associated with sleep abnormalities.

Keywords CKD · Gene expression · Orexin · Sleep abnormalities

\section{Introduction}

Various sleep abnormalities, such as delayed sleep onset, frequent awakening and daytime sleepiness deteriorate the quality of life in many patients with chronic kidney disease (CKD), including those on haemodialysis (HD). Up to $80 \%$ of such patients have been reported to suffer from sleep abnormalities [1-9]. Polysomnographic analysis has revealed a higher prevalence of various types of sleep disorders in CKD patients than in healthy subjects [10].

The sleep cycle consists of 2 different stages, the rapid eye movement (REM) sleep and the non-REM sleep. Recent studies have indicated a relationship between sleep abnormalities, including alterations in REM/non-REM duration, and some psycho-neurological diseases, such as depression [11, 12] and schizophrenia [13, 14]. Changes in the REM/non-REM duration in CKD patients have also been described. Parker et al. reported that HD subjects showed less REM sleep compared with CKD subjects [10]. 
Moreover, Hsu et al. revealed that REM sleep was increased in CKD rats compared with normal rats [15]. These data indicate that the regulation of REM and nonREM sleeps may be disrupted in both patients with CKD and psycho-neurological diseases.

Increasing data have shown that the transition between the REM and non-REM phases is regulated by monoamine, $\gamma$-aminobutyric acid (GABA) and orexin signallings in brainstem cholinergic neurons $[16,17]$. Orexin signalling plays a particularly central role in the regulation of wakefulness and is being investigated as a therapeutic target for insomnia [18-20]. However, the expression of these molecules in the hypothalamus is difficult to measure in patients with insomnia.

Recent studies have revealed that gene expression in peripheral blood cells (PBCs) could be useful for the diagnosis and monitoring of disease activity in psychiatric disorders, such as anorexia nervosa, depression and migraine [21-23]. However, the expression of genes that relate to sleep disorders has not been identified. Thus, we hypothesised that sleep-related gene expression in PBCs of CKD patients may be associated with sleep disorders. To address this hypothesis, we performed polysomnographic analysis in CKD patients and healthy controls. Moreover, the expression of genes related to sleep and awakening, including GABA and orexin, was evaluated using RNA microarrays.

\section{Patients and methods}

\section{Patients}

Polysomnographic analysis was performed overnight to evaluate the REM and non-REM sleeps in 9 CKD patients and 6 controls at Kanazawa University Hospital. We excluded patients with moderate to severe sleep apnoea whose apnoea-hypopnea index was over 25 . There were 7 patients with diabetes in CKD group, and 3 patients in control group. The patient characteristics are summarised in Table 1.

RNA microarray analysis was performed in 19 patients without diabetes, malignant tumour, and severe sleep apnoea. The patients were divided into three groups: HT group ( 8 hypertension patients with eGFR of $>60 \mathrm{~mL} / \mathrm{min} /$ $1.73 \mathrm{~m}^{2}$ ), CKD group (7 patients not on dialysis with eGFR of $<60 \mathrm{~mL} / \mathrm{min} / 1.73 \mathrm{~m}^{2}$ ) and HD group (4 HD patients). The patient characteristics are summarised in Table 2 . The percentage of neutrophils in the peripheral blood was higher in the HD group than in the HT group (HT: 55.2 $12.5 \%$, HD: $68.44 .4 \%, p<0.05)$. Conversely, the percentage of lymphocytes in the peripheral blood was lower in the HD group than in the HT group (HT: $35.412 .1 \%$, HD: $21.14 .9 \%, p<0.05)$.
Table 1 Clinical background for polysomnography

\begin{tabular}{llll}
\hline & CKD & non-CKD & $p$ value \\
\hline No. of patients & 9 & 6 & NS \\
Age (years old) & $71.1 \pm 8.9$ & $67.5 \pm 8.6$ & NS \\
Gender (women/men) & $4 / 5$ & $3 / 3$ & \\
Height $(\mathrm{cm})$ & $153.4 \pm 9.1$ & $157.7 \pm 7.9$ & NS \\
Body weight $(\mathrm{kg})$ & $53.8 \pm 9.3$ & $55.0 \pm 6.6$ & NS \\
BMI $\left(\mathrm{kg} / \mathrm{m}^{2}\right)$ & $22.8 \pm 3.1$ & $22.3 \pm 3.8$ & NS \\
Creatinine $(\mathrm{mg} / \mathrm{dl})$ & $3.8 \pm 2.3$ & $0.7 \pm 0.2$ & $<0.05$ \\
eGFR $\left(\mathrm{ml} / \mathrm{min} / \mathrm{m}^{2}\right)$ & $18.9 \pm 14.2$ & $80.9 \pm 10.9$ & $<0.05$ \\
Urea nitrogen $(\mathrm{mg} / \mathrm{dl})$ & $57.1 \pm 26.5$ & $16.8 \pm 2.8$ & $<0.05$ \\
Haemoglobin $(\mathrm{g} / \mathrm{dl})$ & $10.3 \pm 1.1$ & $12.9 \pm 0.6$ & $<0.05$ \\
Calcium $(\mathrm{mg} / \mathrm{dl})$ & $8.6 \pm 0.5$ & $9.3 \pm 0.6$ & NS \\
Phosphorus $(\mathrm{mg} / \mathrm{dl})$ & $4.2 \pm 0.7$ & $3.7 \pm 0.2$ & NS \\
\hline
\end{tabular}

After informed consent was obtained, blood samples were collected upon entry to the study. Then, we used RNA microarray to evaluate the genes related to sleep and awakening. This study was approved by the ethics committee of Kanazawa University (IRB approval number 907-3).

\section{RNA isolation, microarray hybridization and analysis}

Blood specimens $(2.5 \mathrm{ml})$ were collected from AM 8 to 10 ', before hemodialysis in PAXgene tubes from each patient. They were incubated at room temperature for $4 \mathrm{~h}$ for RNA stabilisation and then stored at $-80{ }^{\circ} \mathrm{C}$. RNA was extracted from whole blood using the PAXgene Blood RNA System Kit following the manufacturer's guidelines. The quality of the purified RNA was verified using an Agilent 2001 bioanalyzer (Agilent Technologies, Palo Alto, CA) and RNA concentrations were determined using a NanoDrop ND-1000 spectrophotometer (NanoDrop Technologies, Wilmington, DE). Total RNA (100 ng) was used for the generation of biotin-labelled cRNA using the Affymetrix Two-Cycle cDNA Synthesis Kit (Affymetrix, Santa Clara, CA). After the second cycle cDNA synthesis, biotin-labelled cRNA was generated using the Affymetrix IVT labelling kit. The labelled cRNA was cleaned, quantified and hybridised to Affymetrix HG-U133 Plus2.0 GeneChips after fragmentation. The chips were washed and stained with streptavidin phycoerythrin was amplified using a biotinylated antibody solution in an Affymetrix Fluidics Station 450 according to the Affymetrix GeneChip protocol. The arrays were scanned, data were extracted using the GeneChip scanner 3000 (Affymetrix, Santa Clara, CA) and raw data file formats were generated using the Gene Chip Operating Software (GCOS). 
Table 2 Clinical findings and data of patients for DNA array analysis

\begin{tabular}{llll}
\hline & HD & CKD & HT \\
\hline No. of patients & 4 & 7 & 8 \\
Age (years old) & $57.8 \pm 10.9$ & $70.9 \pm 15.6$ & $61.6 \pm 9.4$ \\
Gender (women/men) & $1 / 3$ & $5 / 2$ & $4 / 4$ \\
White blood cell counts $(/ \mu \mathrm{l})$ & $4000 \pm 780$ & $4930 \pm 650$ & $4800 \pm 1080$ \\
Neutrophils $(\%)$ & $68.4 \pm 4.4^{*}$ & $57.3 \pm 5.9$ & $55.2 \pm 12.5$ \\
Lymphocytes $(\%)$ & $21.1 \pm 4.9^{*}$ & $35.4 \pm 6.7$ & $35.4 \pm 12.1$ \\
Monocytes $(\%)$ & $5.2 \pm 2.9$ & $5.4 \pm 1.1$ & $5.7 \pm 1.3$ \\
Haemoglobin $(\mathrm{g} / \mathrm{dl})$ & $11.2 \pm 1.5^{*}$ & $11.7 \pm 1.2^{*}$ & $14.2 \pm 0.9$ \\
Platelets $\left(\times 10^{3} / \mathrm{dl}\right)$ & $14.6 \pm 1.6^{*, \#}$ & $20.7 \pm 1.4$ & $23.0 \pm 4.9$ \\
Creatinine $(\mathrm{mg} / \mathrm{dl})$ & $13.4 \pm 2.3^{*, \#}$ & $1.1 \pm 0.5^{*}$ & $0.6 \pm 0.1$ \\
eGFR $\left(\mathrm{ml} / \mathrm{min} / \mathrm{m}^{2}\right)$ & $2.7 \pm 0.6^{*}, \#$ & $45.0 \pm 13.8^{*}$ & $96.0 \pm 9.0$ \\
Albumin $(\mathrm{g} / \mathrm{dl})$ & $4.3 \pm 0.3$ & $4.2 \pm 0.4$ & $4.5 \pm 0.3$ \\
Calcium $(\mathrm{mg} / \mathrm{dl})$ & $9.6 \pm 0.5$ & $9.4 \pm 0.4$ & $9.4 \pm 0.3$ \\
Phosphorus $(\mathrm{mg} / \mathrm{dl})$ & $7.1 \pm 1.6^{*, \#}$ & $3.6 \pm 0.5$ & $3.2 \pm 0.4$ \\
\hline$* p<0.05 \mathrm{vs} \mathrm{HT}$ group, ${ }^{\#} p<0.05$ vs CKD group & &
\end{tabular}

\section{Image analysis and data processing}

Both gene expression and pathway analysis were performed using BRB-ArrayTools software (http://linus.nci. nih.gov/BRB-ArrayTools.html). To identify genetic variants, paired $t$ tests were performed using BRB-ArrayTools software to define $p$ values $<0.05$. Hierarchical clustering of gene expression in patients was performed using Java Treeview-1.1. Filtered data were log transformed, normalised, centred and applied to the average linkage clustering with centred correlation. Genes related to sleep and awakening were evaluated by gene expression analysis by BRB-ArrayTools, and change in gene expression patterns was evaluated in relation to the level of renal dysfunction.

\section{Statistical analysis}

The results are expressed as mean values \pm SE. One-way analysis of variance (ANOVA) by the Bonferroni method or the Student's $t$ test was used to determine the significance of differences in clinical characteristics between patients in this study. In all analyses, statistical significant was set at $p$ value $<0.05$.

\section{Results}

\section{Duration of the REM/non-REM sleeps during total sleep time in CKD patients and healthy controls}

Polysomnography of CKD patient (Fig. 1a) and control (Fig. 1b) was shown. In CKD patients, REM sleep appeared at the early phase of sleep, whereas it appeared at mid to late phase of sleep in controls. Although the total sleep time was similar, the duration of the REM/non-REM sleeps was different between CKD patients and controls. Compared with controls, the percentage of REM sleep time tended to be longer and that of non-REM sleep time tended to be shorter in CKD patients (Fig. 1c). These results indicate that the cycle of REM and non-REM sleep was disrupted in CKD patients.

\section{Analysis of hierarchical clustering of sleep-related gene expression in PBCs of HD, CKD and hypertension patients}

Next, we evaluated the expression of sleep-related genes in PBCs of HD or CKD patients and hypertensive controls. We identified 165 probe sets, which consists of 68 sleep and awakening related genes according to BRBArrayTools software (Table 3). The results of the hierarchical clustering analysis showed different patterns of expression of these 165 probe sets, 68 genes in HD patients (Fig. 2). The RNA microarray dataset of this study was uploaded in GEO (NCBI). The accession number is GSE70528.

\section{Regulation of signalling pathway-related genes in HD and CKD patients}

Pathway analysis of these 165 probe sets, 68 sleep-related genes revealed that cell signalling pathways, such as $\mathrm{Ca}^{2+} /$ calmodulin-dependent protein kinase activation, extracellular signal-regulated kinase (ERK) 5 and p38 
a

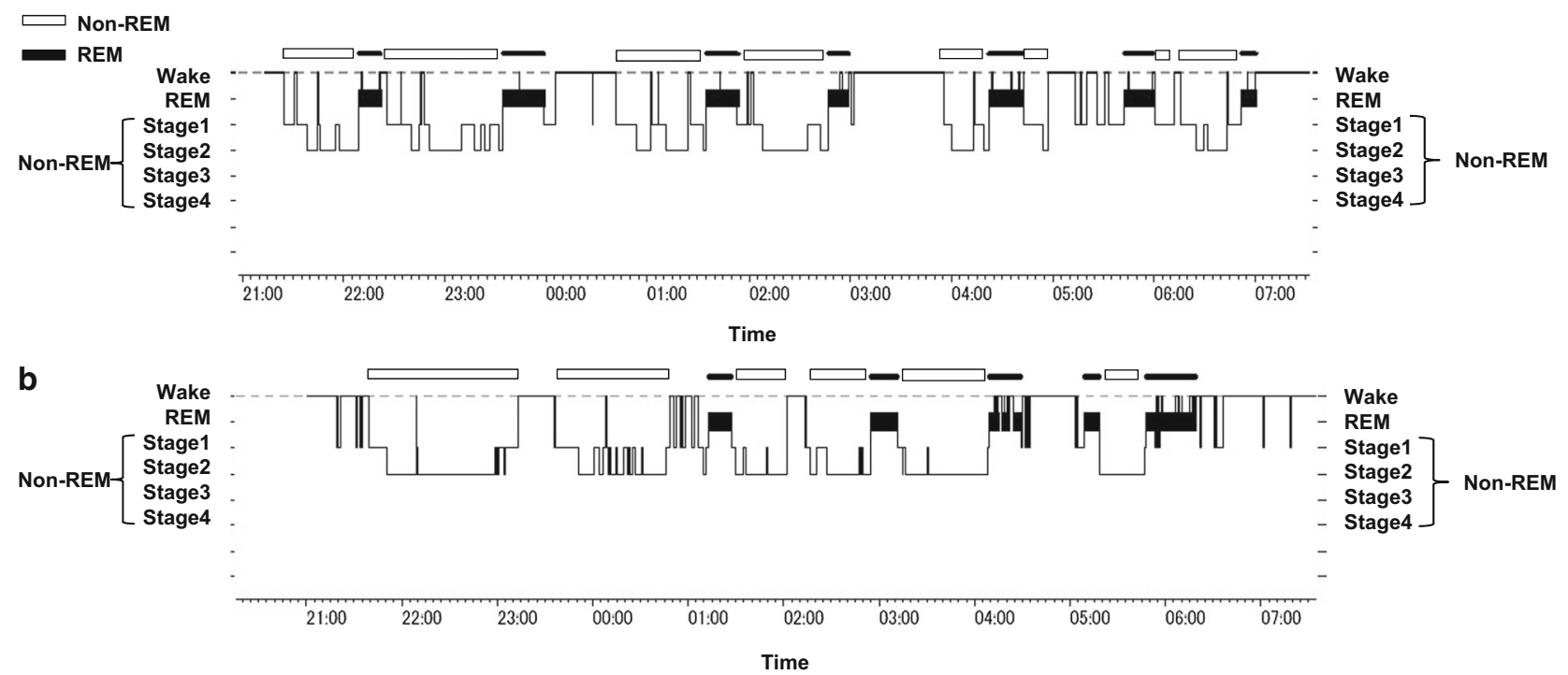

C Total sleep time (min)
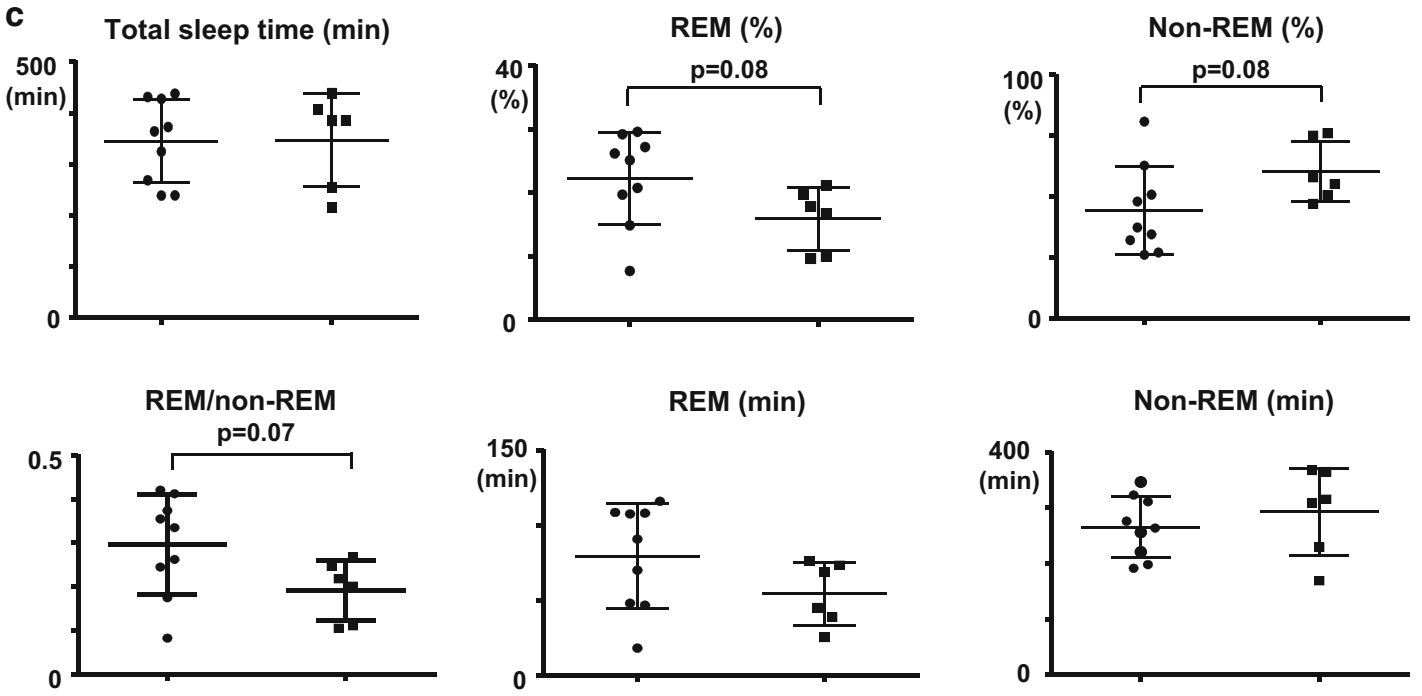

Non-REM (min)

- $\operatorname{CKD}(n=9)$

Control $(n=6)$
Fig. 1 The duration of the REM/non-REM sleeps during total sleep time was different between CKD patients and controls. Polysomnography of CKD patient (a) and control (b). CKD patients tended to be disrupted of REM/non-REM cycle in sleep time. In CKD patients, REM sleep appeared at the early phase of sleep, whereas, it appeared at mid to late phase of sleep in controls. c Although the total sleep

mitogen-activated protein kinase (MAPK), were regulated in HD and CKD patients (Table 4).

\section{Correlation of renal function with mRNA expression levels of GABA receptors, noradrenaline receptors, dopamine receptors and histamine receptors}

Next, we analysed whether renal function could change the expression of REM/non-REM sleep-related genes in PBCs. mRNA expression levels of GABBR2 (a GABA receptor), ADARA1A (a noradrenaline receptor), DRD1 (a dopamine time was similar, the duration of the REM/non-REM sleeps was different between CKD patients and healthy controls. Compared with healthy controls, the percentage of REM sleep time tended to be longer and that of non-REM sleep time tended to be shorter in CKD patients

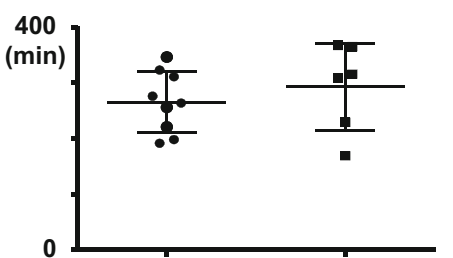

receptor) and HRH1 (a histamine receptor) were found to be inversely correlated with renal function (Fig. 3).

\section{Correlation of renal function with mRNA expression of orexin and its receptor}

Recent studies have revealed that REM sleep amount is greatly influenced by orexin signalling. Thus, we evaluated the mRNA expression of these molecules in PBCs. The mRNA expression of orexin and its receptor was inversely correlated with renal function (Fig. 4). 
Table 3 Sleep and awakening related 165 probe sets, 68 genes

\begin{tabular}{llll}
\hline AANAT & CYP7B1 & JUN & PER3 \\
ACADS & DBP & KCNH7 & PHLPP \\
ARNTL & DDC & KCNMA1 & PLCB4 \\
ARNTL2 & EGFR & KMO & PPP5C \\
ATOH7 & EGR3 & MAT2A & PRF1 \\
BHLHE40 & ERBB3 & MTNR1A & PRL \\
BHLHE41 & F7 & NA & PROK2 \\
CCRN4L & FBXL3 & NFIL3 & PROKR2 \\
CDK4 & FBXW11 & NPAS2 & RORA \\
CLOCK & FDFT1 & NR1D1 & RORB \\
CREB1 & GLO1 & NR1H3 & SLC9A3 \\
CREM & HAT1 & NR2F6 & SUMO2 \\
CRX & HEBP1 & OPN3 & SUMO3 \\
CRY1 & HLF & OPN4 & THRA \\
CRY2 & HS3ST2 & PAX4 & TIMELESS \\
CSNK1D & HTR7 & PER1 & VIP \\
CSNK1G2 & HTR7P & PER2 & VIPR2 \\
\hline
\end{tabular}

\section{Discussion}

We performed polysomnographic analysis to show that the duration of the REM/non-REM sleeps during total sleep time was different between CKD patients and controls. Hierarchical clustering analysis of the expression of sleeprelated genes in PBCs showed different patterns between $\mathrm{HD}$ patients and CKD/hypertension patients. mRNA expression levels of GABBR2, ADARA1A, DRD1 and HRH1 showed an inverse correlation with renal function. The mRNA expression of orexin and its receptors was also inversely correlated with renal function.

HD or CKD patients experience various sleep disorders, such as delayed sleep onset, frequent awakening and daytime sleepiness. Although uremic substances would be appropriate causal candidates, detailed mechanisms have not yet been elucidated. Polysomnography revealed that CKD patients tended to have longer REM sleep than healthy controls in this study. Consistent with this finding, Hsu et al. revealed that REM sleep was increased in CKD rats compared with normal rats [15]. In addition, Parker et al. reported that HD subjects showed less REM sleep compared with CKD patients [10]. Moreover, another group showed that there was no difference in REM sleep time between CKD and HD patients [24]. Although these data indicate that renal dysfunction and dialysis may affect the duration of REM/non-REM sleep, more studies are needed to clarify the sleep disorders of CKD patients.

Pathway analysis of 165 probe sets, 68 sleep-related genes revealed that some signalling pathways, such as $\mathrm{Ca}^{2+} /$ calmodulin-dependent protein kinase, ERK 5 and p38 MAPK, were up/down regulated in CKD patients. Previous studies have revealed that ERK/MAPK signalling in the central nervous system (CNS) contributes to REM sleep $[25,26]$. However, the impact of those signalling pathways in PBCs on sleep disorders remains to be investigated.

GABA signalling has been reported to play a central role both in REM-off and REM-on areas of the brain that regulate the transition between the REM and non-REM sleeps [16]. Orexin is expressed in the lateral hypothalamic area and is known to promote wakefulness [18, 19]. While sleep-related molecules have mainly been investigated in the CNS, some studies have examined the expression of these molecules in the PBCs of patients with psychiatric disorders. Rotter et al. reported orexin expression and promoter methylation in the peripheral blood of patients suffering from major depressive disorders [27]. Plummer et al. reported on GABA expression in peripheral blood leukocytes of patients with migraines [22]. These reports indicate that the expression of these sleep-related molecules in the peripheral blood may be associated with neurological disorders, including sleep disorders. In our study, the mRNA expression of some sleep-related genes, such as noradrenaline receptor, dopamine receptor, GABA receptor, orexin and its receptors, was inversely correlated in CKD patients. These data raise the possibility that these up-regulated molecules in PBCs may be related to the
Fig. 2 Hierarchical clustering analysis of whole blood samples from HD, CKD and hypertension patients. The results of hierarchical clustering analysis showed different patterns of expression of these 165 probe sets, 68 genes in HD patients

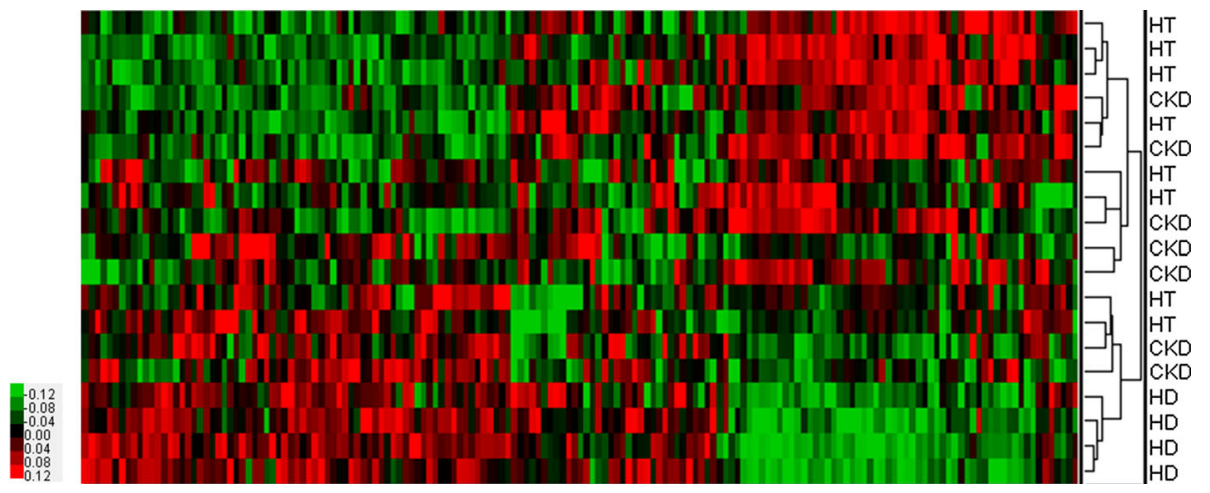


Table 4 Gene array data indicated that some sleep and awakening related genes were varied in CKD and HD group

\begin{tabular}{lcc}
\hline Pathway description & No. of genes & $\begin{array}{l}\text { HT vs. HD } \\
p \text { value }\end{array}$ \\
\hline $\mathrm{Ca}^{2+} /$ calmodulin-dependent protein kinase activation & 0.00007 \\
Transcription regulation by methyltransferase of CARM1 & 7 & 0.00007 \\
Transcription factor CREB and its extracellular signals & 7 & 0.00007 \\
Role of Erk5 in neuronal survival & 7 & 0.00007 \\
Calcium signalling by HBx of hepatitis B virus & 7 & 0.00007 \\
Human cytomegalovirus and map kinase pathways & 7 & 0.00007 \\
Inhibition of huntington & 7 & 0.00007 \\
Melanocyte development and pigmentation pathway & 0.00007 \\
p38 MAPK signalling pathway & 7 & 0.00007 \\
Antigen processing and presentation & 7 & 0.00007 \\
Oxidative stress induced gene expression via Nrf2 & 7 & 0.00866 \\
Signalling pathway from G-protein families & 7 & 0.00038 \\
Hypoxia-inducible factor in the cardiovascular system & 11 & 0.00866 \\
MAP Kinase signalling pathway & 11 & 0.00866 \\
Repression of pain sensation by the transcriptional regulator DREAM & 11 & 0.00866 \\
Hedgehog signalling pathway & 11 & 0.00866 \\
\hline
\end{tabular}

Fig. 3 mRNA expression levels of GABA receptor, noradrenaline receptor, dopamine receptor and histamine receptor showed an inverse correlation with renal function. mRNA expression levels of GABBR2 (a GABA receptor), ADARA1A (a noradrenaline receptor), DRD1 (a dopamine receptor) and HRH1 (a histamine receptor) were inversely correlated with renal function
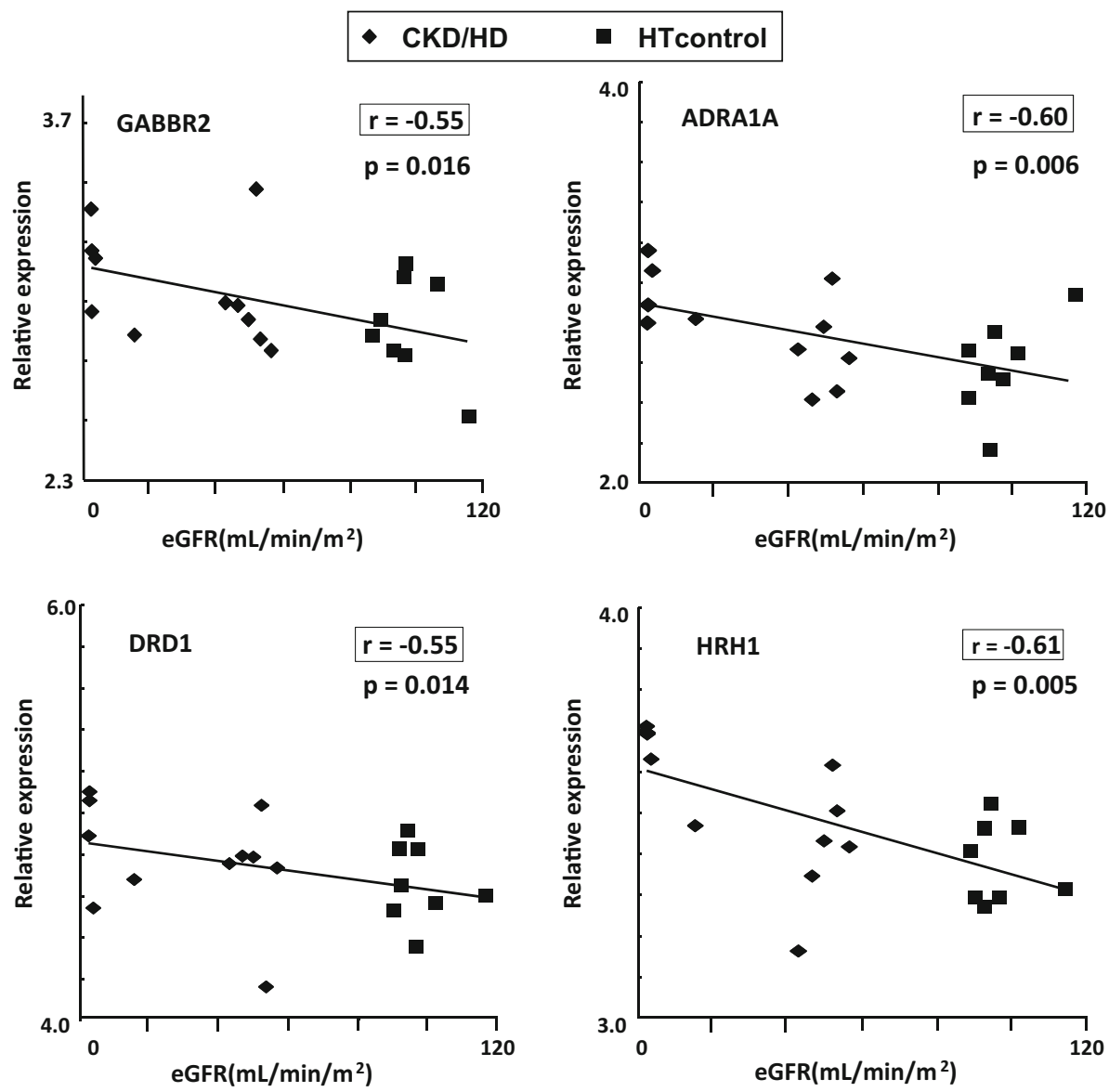

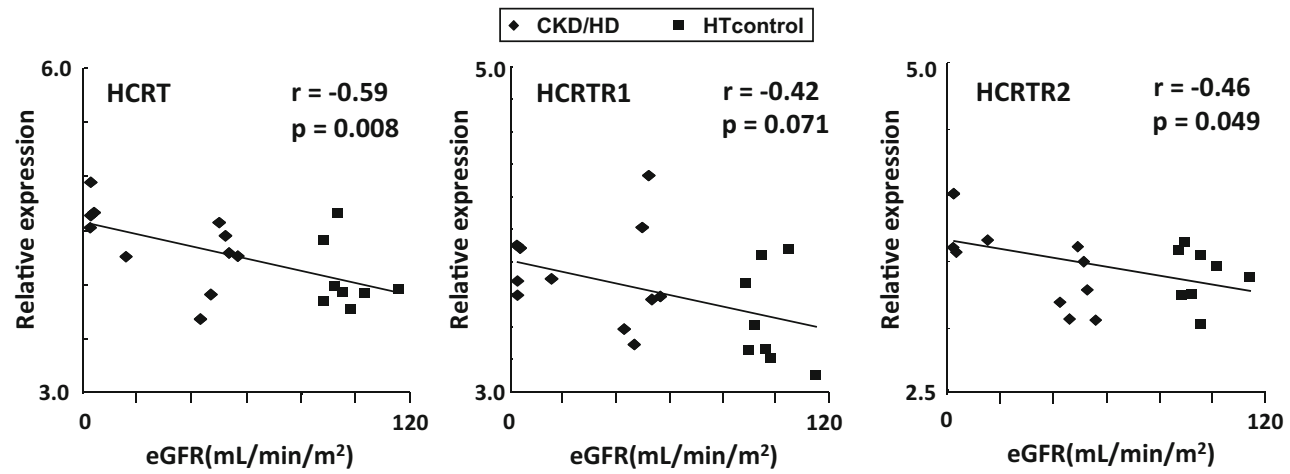

Fig. 4 The mRNA expression of orexin and its receptor showed an inverse correlation with renal function. In addition to monoamine receptors, the mRNA expression of orexin and its receptor was also inversely correlated with renal function

abnormality of REM/non-REM duration in CKD patients. However, the contribution of these sleep-related molecules in PBCs to disease pathophysiology requires further investigation. In this study, we have some limitations. In the polysomnographic analysis, we examined the CKD patients both with and without diabetes in order to explore the overall trend in CKD patients. While the sleep disturbance was revealed in relation to CKD, the influence of diabetes was not excluded in the study. In addition, we did not evaluate urinary protein of all patients. Therefore, we are not able to examine the relationship between urinary protein and gene expression.

\section{Conclusion}

In summary, we reported on the disrupted REM/non-REM sleep in CKD patients. Moreover, the expression of orexin, orexin receptor and some monoamine receptors genes in the PBCs of CKD patients was inversely correlated with renal function. Taken together, these results indicate a possible relationship between sleep-related gene expressions in the PBCs of CKD patients and sleep disorders.

\section{Compliance with ethical standards}

Conflict of interest The authors have declared that no conflict of interest exists.

\section{References}

1. Holley JL, Nespor S, Rault R. A comparison of reported sleep disorders in patients on chronic hemodialysis and continuous perito-neal dialysis. Am J Kidney Dis. 1992;19:156-61.

2. Walker S, Fine A, Kryger MH. Sleep complaints are common in a dialysis unit. Am J Kidney Dis. 1995;26:751-6.

3. Williams SW, Tell GS, Zheng B, et al. Correlates of sleep behavior among hemodialysis patients. Am $\mathrm{J}$ Nephrol. 2002;22:18-28.
4. McClellan WM, Anson C, Birkeli K, et al. Functional status and quality of life: predictors of early mortality among patients entering treatment for end stage renal disease. J Clin Epidemiol. 1991;44:83-9.

5. Pressman MR, Benz RL. High incidence of sleep disorders in end stage renal disease. Sleep Res. 1995;24:417.

6. Eryavuz N, Yuksel S, Acarturk G, et al. Comparison of sleep quality between hemodialysis and peritoneal dialysis patients. Int Urol Nephrol. 2008;40:785-91.

7. Hanly PJ, Pierratos A. Improvement of sleep apnea in patients with chronic renal failure who undergo nocturnal hemodialysis. N Engl J Med. 2001;344:102-7.

8. Iliescu E, Coo H, McMurray $\mathrm{MH}$, et al. Quality of sleep and health-related quality of life in hemodialysis patients. Nephrol Dial Transpl. 2003;18:126-32.

9. Unruh ML, Buysse DJ, Amanda Dew M, et al. Sleep quality and its correlates in the first year of dialysis. Clin J Am Soc Nephrol. 2006;1:802-10.

10. Parker KP, Bliwise DL, Bailey JL, et al. Polysomnographic measures of nocturnal sleep in patients on chronic, intermittent daytime haemodialysis vs those with chronic kidney disease. Nephrol Dial Transpl. 2005;20:1422-8.

11. Arana-Lechuga Y, Nuñez-Ortiz R, Terán-Pérez G, et al. SleepEEG patterns of school children suffering from symptoms of depression compared to healthy controls. World J Biol Psychiatry. 2008;9:115-20.

12. Benca RM, Obermeyer WH, Thisted RA, et al. Sleep and psychiatric disorders. A meta-analysis. Arch Gen Psychiatry. 1992;49:651-68.

13. Benson KL, Sullivan EV, Lim KO, et al. Slow wave sleep and computed tomographic measures of brain morphology in schizophrenia. Psychiatry Res. 1996;60:125-34.

14. Chouinard S, Poulin J, Stip E, et al. Sleep in untreated patients with schizophrenia: a meta-analysis. Schizophr Bull. 2004;30:957-67.

15. Hsu CY, Chang FC, Ng HY, et al. Disrupted circadian rhythm in rats with nephrectomy-induced chronic kidney disease. Life Sci. 2012;91:127-31.

16. Lu J, Sherman D, Devor M, et al. A putative flip-flop switch for control of REM sleep. Nature. 2006;441:589-94.

17. Mallick BN, Singh A. REM sleep loss increases brain excitability: role of noradrenaline and its mechanism of action. Sleep Med Rev. 2011;15:165-78.

18. Sakurai T, Amemiya A, Ishii M, et al. Orexins and orexin receptors: a family of hypothalamic neuropeptides and G proteincoupled receptors that regulate feeding behavior. Cell. 1998;92:573-85. 
19. Brisbare-Roch C, Dingemanse J, Koberstein R, et al. Promotion of sleep by targeting the orexin system in rats, dogs and humans. Nat Med. 2007;13:150-5.

20. Winrow CJ, Gotter AL, Cox CD, et al. Pharmacological characterization of MK-6096-a dual orexin receptor antagonist for insomnia. Neuropharmacology. 2012;62:978-87.

21. Weiss D, Infante-Duarte $\mathrm{C}$, Salbach-Andrae $\mathrm{H}$, et al. Preproenkephalin expression in peripheral blood mononuclear cells of acutely underweight and recovered patients with anorexia nervosa. Neuropsychobiology. 2010;62:151-7.

22. Yi Z, Li Z, Yu S, et al. Blood-based gene expression profiles models for classification of subsyndromal symptomatic depression and major depressive disorder. PLoS One. 2012;7:e31283.

23. Plummer PN, Colson NJ, Lewohl JM, et al. Significant differences in gene expression of GABA receptors in peripheral blood leukocytes of migraineurs. Gene. 2011;490:32-6.

24. Roumelioti ME, Ranpuria R, Hall M, et al. Abnormal nocturnal heart rate variability response among chronic kidney disease and dialysis patients during wakefulness and sleep. Nephrol Dial Transpl. 2010;25:3733-41.

25. Ravassard P, Pachoud B, Comte JC, et al. Paradoxical (REM) sleep deprivation causes a large and rapidly reversible decrease in long-term potentiation, synaptic transmission, glutamate receptor protein levels, and ERK/MAPK activation in the dorsal hippocampus. Sleep. 2009;32:227-40.

26. Luo J, Phan TX, Yang Y, Garelick MG, Storm DR. Increases in cAMP, MAPK activity, and CREB phosphorylation during REM sleep: implications for REM sleep and memory consolidation. J Neurosci. 2013;33:6460-8.

27. Rotter A, Asemann R, Decker A, Kornhuber J, Biermann T. Orexin expression and promoter-methylation in peripheral blood of patients suffering from major depressive disorder. J Affect Disord. 2011;131:186-92. 